\title{
THE PLACE OF TRUECPR FEEDBACK DEVICE IN CARDIOPULMONARY RESUSCITATION. SHOULD WE USE IT? A RANDOMIZED PILOT STUDY
}

\author{
Jolanta Majer', Agnieszka Madziala', Agata Dabrowska², Marek Dabrowski \\ ${ }^{1}$ Department of Emergency Medicine, Medical University of Warsaw, Warsaw, Poland \\ ${ }^{2}$ Department of Medical Rescue, Poznan University of Medical Sciences, Poznan, Poland \\ ${ }^{3}$ Chair and Department of Medical Education, Poznań University of Medical Sciences, Poznan, Poland
}

\begin{abstract}
INTRODUCTION: Sudden cardiac arrest is a challenge for medical personnel as well as a high socio-economic burden. Many authors indicate that the quality of cardiopulmonary resuscitation, including chest compressions performed without an assisted device, may raise doubts due to failure to achieve the value of chest compressions recommended by the guidelines of the American Cardiac Society. All kinds of devices supporting cardiopulmonary resuscitation, including CPR feedback devices, may be helpful in this regard.
\end{abstract}

METHODS: The study involved 38 nurses who were tasked with conducting a 2-minute cardiopulmonary resuscitation cycle based on continuous chest compression. chest compressions were carried out in two scenarios: with and without the use of a TrueCPR feedback device. Both the order of the participants as well as the research methods were random. For this purpose, the coin-toss technique was used. Statistical analysis was conducted using the Statistica 12EN system.

RESULTS: The average chest compression rate in the case of non-instrumental compression was $131 \pm 12$ compressions per minute and was statistically significantly higher than in the case of using the TrueCPR device $(P=0.022)$. Mean chest compression depth with and without the TrueCPR device showed significant variation, $38 \pm 11 \mathrm{~mm}$ for manual chest compression, and $52 \pm 6 \mathrm{~mm}$ for TrueCPR $(P<0.001)$. Full chest recoil for manual chest compression and compression using the TrueCPR device was $46 \pm 19 \%$, respectively. $75 \pm 18 \%(P<0.001)$.

CONCLUSIONS: The use of the TrueCPR device in simulated resuscitation conditions has a statistically significant effect on the improvement of chest compression parameters, including the frequency and depth of chest compressions as well as the degree of correctness of chest relaxation.

KEY WORDS: cardiopulmonary resuscitation, chest compression, quality, nurse, medical simulation

Disaster Emerg Med J 2018; 3(4): 131-136

\section{INTRODUCTION}

Sudden cardiac arrest (SCA) is a challenge for medical personnel as well as a high socio-economic burden [1]. In the United States of America, the incidence of SCA ranges between
200,000 to 300,000 cases per year [2], which translates to around 52 cases per 100.000 people [3, 4]. Data from the American Society of Cardiology indicates that in 2017 there were 356.500 cases of sudden cardiac arrest outside the hospital, during which 
the resuscitation conducted by bystanders was only $45.7 \%$ of cases, and the survival rate was $11.4 \%$. With regard to in-hospital cardiac arrest, there were 209.000 cases with a resuscitation rate of $23.8 \%$ [5, 6]. As indicated by the studies by Gräser et al., The prevalence of community-acquired cardiac arrest in European conditions is lower and amounts to approximately 40 cases per 100.000 adults [7]. In Polish conditions, Gach et al. Assessing the incidence of OHCA in the area of Bielsko-Biała showed that it was 170 cases per 100.000 people, with OHCA as men being 243/100.000 and more than twice as frequent as women - 99/100.000 people [8].

Basic life support is a key element of resuscitation. They are based on chest compressions and rescue breaths in a ratio of 30:2. Chest compressions should be carried out in accordance with the guidelines of the European Resuscitation Council (ERC) [9] or the American Society of Cardiology (AHA) [10]. According to the above guidelines, the depth of chest compressions in an adult should be between 50 and $60 \mathrm{~mm}, 50 \mathrm{~mm}$ in the case of a child, and $1 / 3$ of the sagittal dimension of the chest in a newborn, giving a depth of about $40 \mathrm{~mm}$. However, the frequency of chest compressions, which, regardless of the age group, should be between 100 and 120 compressions per minute, is also important $[11,12]$. The guidelines also emphasize the correctness of chest relaxation after each compression and the need to minimize breaks in chest compressions. The rescue breaths should be performed with the tidal volume intended for a given age group. In the case of adults, it is assumed that the tidal volume is 6-7 $\mathrm{mL}$ for each kilogram of body weight, while in the case of children $8-10 \mathrm{~mL} / \mathrm{kg} \mathrm{m}$.c. The rescue breathing is considered effective if it caused a gentle rise of the patient's chest $[13,14]$. However, as many authors point out, the quality of cardiopulmonary resuscitation, including chest compressions performed in a non-instrumental manner, may raise doubts [15-17]. In this context, audiovisual devices for compressing the chest may be helpful in indicating the depth of chest compressions in real time, or chest relaxation rates $[18,19]$. The range of displayed data depends on the device model.

One of the most advanced devices supporting resuscitation is the TrueCPR device (Physio-Control, Redmond, VA, USA). The device is made of a pad and a chest pad attached to it (Fig. 1). The device works on the principle of electromagnetic signal reading between the back washer and the chest cover $[20,21]$.

The pad should be placed under the patient's back and the pad should be placed on the chest so that the yellow hand pad is in the middle of the chest in the lower half of the sternum (Fig. 2).

If the back pad was placed in the side position, the chest cover should be rotated 180 degrees (Fig. 3).

The chest pad is built from the display and pad, which is the place of pressure. In addition, there are three buttons on the pad. The device's on/off button is marked in green; metronome mute button and button referring to the device's operating mode for intubated patients where continuous chest compressions are performed (Fig. 4).

The display indicating the quality of chest compressions indicates:

- the correctness of chest relaxation - target zone of relaxation (the light green color is changed to dark green when the tightness of the chest is completely released);

- the frequency of compressions (the result is presented as the number of compressions per minute. In the case when pressures are interrupted, the time of inactivity appears on the counter);

- the depth of pressure (the color changes from light green to dark green when the pressure of the chest is in the range from 50 to $60 \mathrm{~mm}$ );

- history of chest compression depth (gray or dark green segment in the outer circle indicates the depth of the previous pressure);

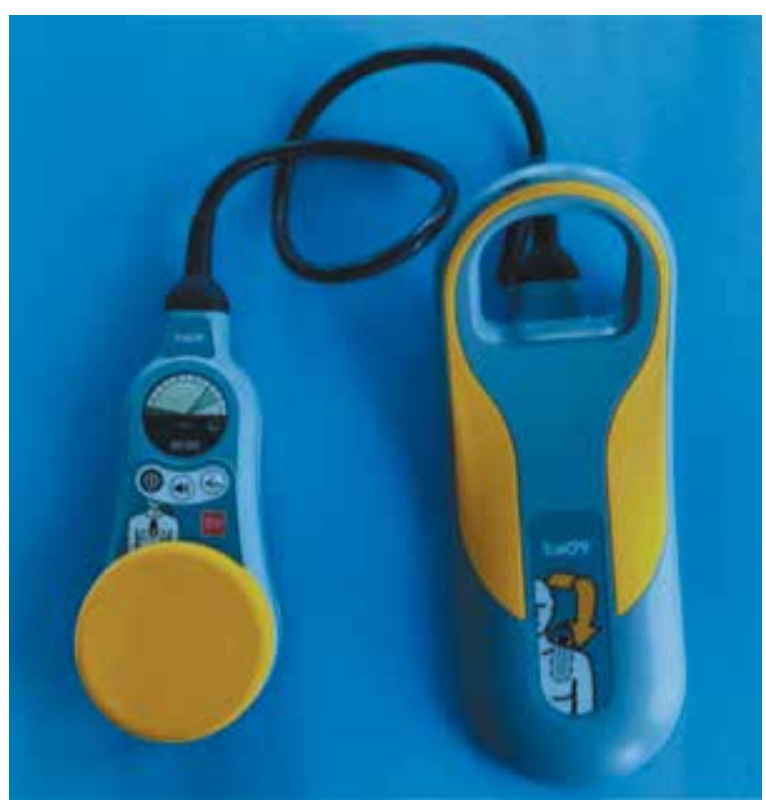

FIGURE 1. TrueCPR device 


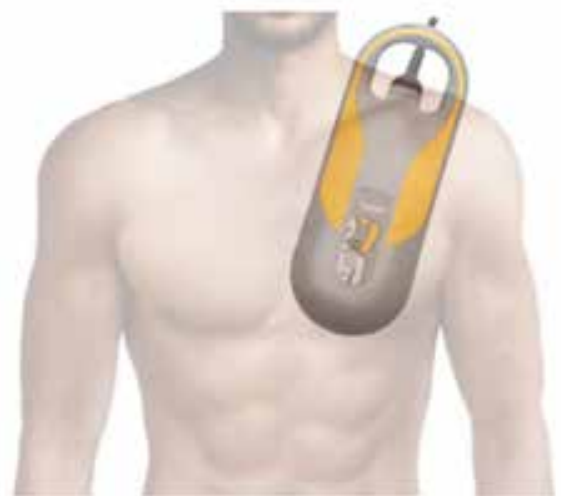

location of the back pad

FIGURE 2. The recommended arrangement of the TrueCPR device

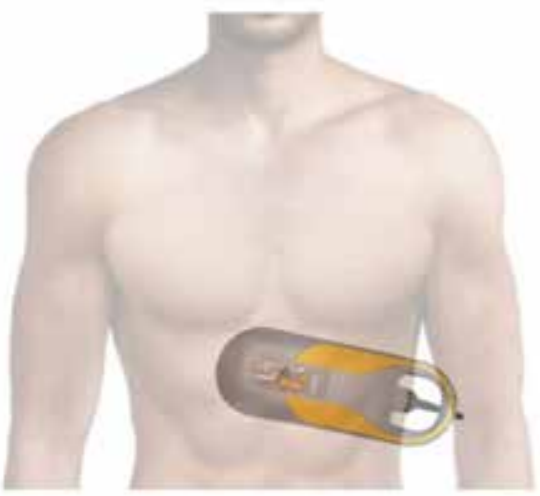

location of the back pad

FIGURE 3. The alternative arrangement of the TrueCPR device

- battery discharge indicator (the indicator appears when the status of the battery charge is lower than the level enabling 25-minute resuscitation);

- time from switching on the device;

- operating indicator in intubated patient mode.

The aim of the study was to assess the impact of using the TrueCPR device by nurses on the quality of chest compression during simulated cardiopulmonary resuscitation.

\section{METHODS}

Thirty-eight nurses participating in training in basic resuscitation procedures accredited by the American Heart Association were qualified for the study. Voluntary informed consent was obtained from each participant. Exclusion criteria from the study were back or wrist injuries, which could reduce the quality of chest compression. An additional criterion excluded from the study was pregnancy.

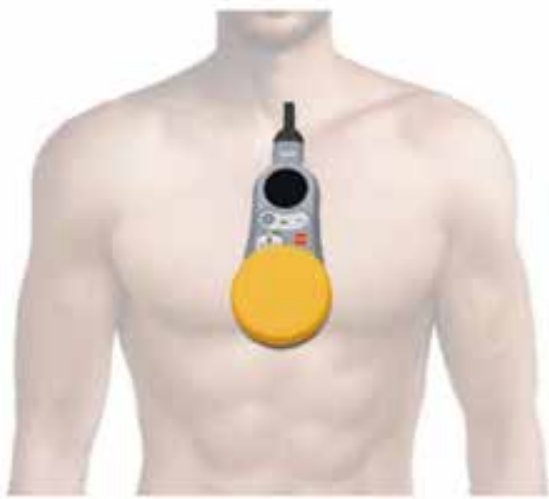

location of the chest pad

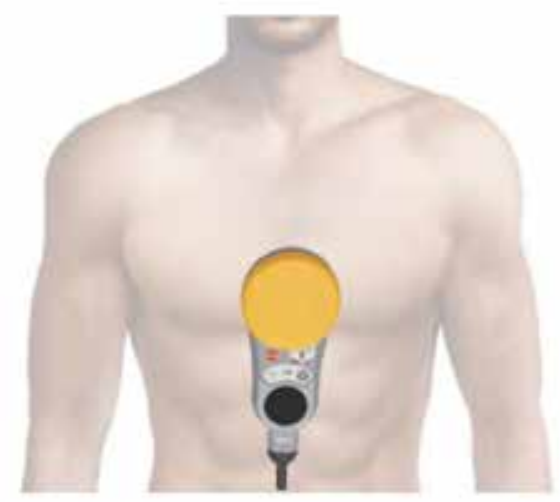

location of the chest pad

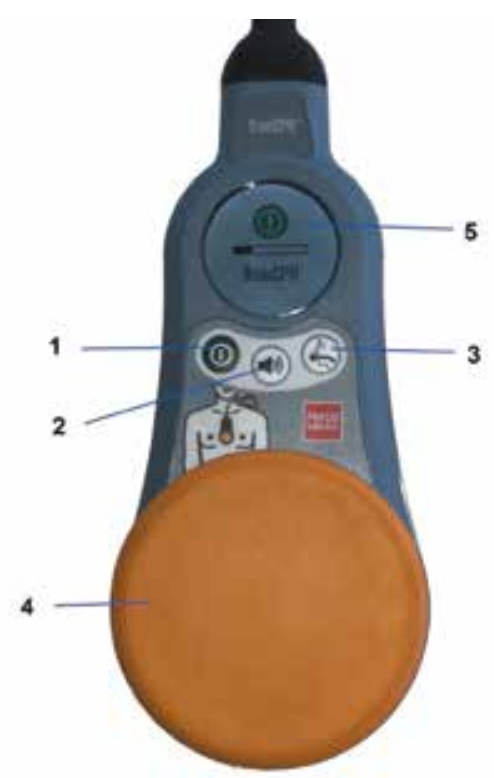

FIGURE 4. Construction of the chest overlay of the TrueCPR device. Legend: (1) on/off button; (2) mute button; (3) change of mode in the case of an intubated patient; (4) hand pad; (5) display of resuscitation parameters 
Prior to the study, the participants participated in the instruction on the correct application of the TrueCPR device, after which they had 10 minutes of practical training. Then, in a cross-randomized manner, they performed a 2-minute cycle of continuous chest compression using an adult simulator - Resusci Anne QCPR (Laerdal, Norway). Resuscitation was performed based on two research scenarios:

A) Scenario A - chest compressions in an unassisted manner;

B) Scenario B - chest compression using the TrueCPR feedback device.

Randomization took place using the coin tossing technique. In this way, the respondents were divided into two groups. Group I began resuscitation based on Scenario A, and Group B using Scenario B. After the resuscitation cycle, participants had a 10-minute break after resuscitation based on the second scenario. A graphical representation of the randomization procedure is shown in Figure 5.

Chest compression parameters such as the frequency of chest compressions, the depth of chest compressions and the degree of complete chest relaxation were analyzed. The values recommended by the guidelines of the American Society of Cardiology were considered the reference values.

Statistical analysis was performed using the Statistica 12EN for Windows software. Chi-squared analysis, mean, standard deviation, Wilcoxon signed rank test, Mann-Whitney $\mathrm{U}$ test were employed. The significance level was set at $p<0.05$.

\section{RESULTS}

The study involved 38 nurses, whose average age was $36 \pm 7$ years, and the average length of service was $14 \pm 8$ years.
The summary of the results obtained is presented in Table 1.

The average chest compression rate in the case of non-instrumental compression was $131 \pm 12$ compressions per minute and was statistically significantly higher than in the case of using the TrueCPR device ( $P=0.022)$.

Mean chest compressions depth with and without the TrueCPR device showed significant variation, $38 \pm 11 \mathrm{~mm}$ for manual chest compression, and $52 \pm 6 \mathrm{~mm}$ for TrueCPR $(P<0.001)$.

Full chest recoil for manual chest compression and compression using the TrueCPR device was $46 \pm 19 \%$ and $75 \pm 18 \%$, respectively $(P<0.001)$.

\section{DISCUSSION}

The study showed a significant advantage of CPR using the TrueCPR feedback device over manual chest compressions. The American Society of Cardiology now recommends that teaching chest compressions during courses are conducted using CPR feedback devices, which facilitates the control of the appropriate chest compression depth, as well as indicates to the course participant at what depth chest compressions should be performed [22, 23]. Of course, CPR devices are also used during real CPR.

It is difficult to achieve optimal depth and chest compressions according to the resuscitation guidelines recommendations of many people's [24, 25]; however, cardiopulmonary feedback devices may help [26]. In the conducted study comparing the quality of chest compressions with and without the TrueCPR device, it showed statistically significant improvement in compression parameters in relation to both depth and frequency of chest compression, as well as the correctness of its relaxation after each

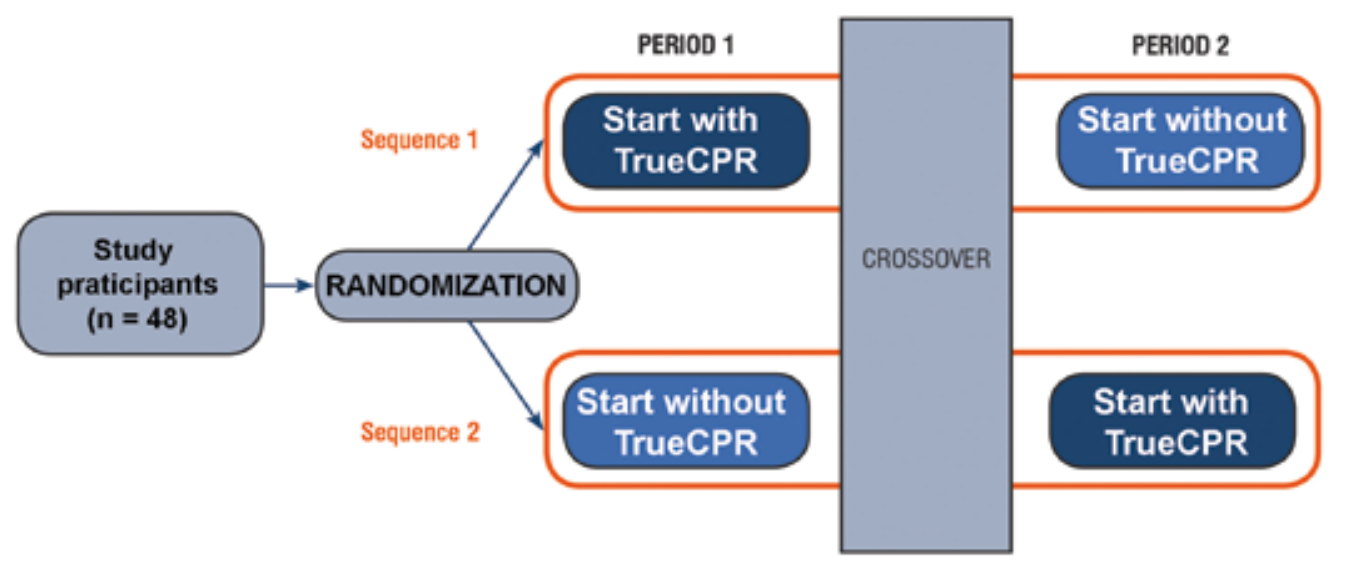

FIGURE 5. Randomization flow chart. 
Table 1. A summary of the results of chest compression

\begin{tabular}{|l|c|c|c|}
\hline Chest compression parameter & CC without TrueCPR & CC with TrueCPR & $p$-value \\
\hline CC rate $[\mathrm{n} / \mathrm{min}]$ & $131 \pm 12$ & $114 \pm 11$ & 0.022 \\
\hline CC depth $[\mathrm{mm}]$ & $38 \pm 11$ & $52 \pm 6$ & $<0.001$ \\
\hline Full chest recoil $[\%]$ & $46 \pm 19$ & $75 \pm 18$ & $<0.001$ \\
\hline
\end{tabular}

CC - chest compression

compression [27]. Truszewski et al. Comparing the quality of chest compressions instrumentally and using the TrueCPR and CPR-Ezy devices during the CPR performed by the nurses also showed an improvement in the chest compressions parameters in the case of using the above devices [28]. Other authors $[18,20]$ also came to similar conclusions. Thanks to its construction, the TrueCPR real-time CPR device indicates the depth and the frequency of chest compressions. Kurowski's research carried out among medical rescuers showed a significant increase in the depth of chest compressions when using the TrueCPR device - $56.5 \mathrm{~mm}$ compared with non-instrumental compression - 49.5mm [21].

In this study we used one of the most advanced devices supporting resuscitation, TrueCPR, but also the use of other devices of this type, as research indicates, improves the quality of cardiopulmonary resuscitation [29-32].

However, it is worth emphasizing that if you do not know how to use your device, attempting to implement it during resuscitation procedures may affect the delay in chest compressions, thereby reducing the chances of spontaneous circulation return.

\section{CONCLUSIONS}

In the conducted simulation test, the use of the TrueCPR device significantly affected the improvement of chest compression parameters, including the frequency and depth of chest compressions as well as the degree of correctness of chest relaxation.

\section{REFERENCES:}

1. Kobayashi D, Kitamura T, Kiyohara K, et al. Cardiopulmonary resuscitation performed by off-duty medical professionals versus laypersons and survival from out-of-hospital cardiac arrest among adult patients. Resuscitation. 2019 [Epub ahead of print]; 135: 66-72, doi: 10.1016/j. resuscitation.2019.01.005, indexed in Pubmed: 30639787.

2. Myerburg RJ. Sudden Cardiac Death: Interface Between Pathophysiology and Epidemiology. Card Electrophysiol Clin. 2017; 9(4): 515-524, doi: 10.1016/j.ccep.2017.07.003, indexed in Pubmed: 29173398.
3. Deyell MW, Krahn AD, Goldberger JJ. Sudden cardiac death risk stratification. Circ Res. 2015; 116(12): 1907-1918, doi: 10.1161/ CIRCRESAHA.116.304493, indexed in Pubmed: 26044247.

4. Kiyohara K, Nishiyama C, Matsuyama T, et al. Out-of-Hospital Cardiac Arrest at Home in Japan. Am J Cardiol. 2019 [Epub ahead of print], doi: 10.1016/j.amjcard.2018.12.038, indexed in Pubmed: 30654927.

5. Takayama W, Endo A, Koguchi $H$, et al. Differences in durations, adverse events, and outcomes of in-hospital cardiopulmonary resuscitation between day-time and night-time: An observational cohort study. Resuscitation. 2019 [Epub ahead of print], doi: 10.1016/j. resuscitation.2019.01.023, indexed in Pubmed: 30708073.

6. Jagosz A, Bursy D, Sobon A, et al. In-hospital sudden cardiac arrest protocol analysis. Kardiol Pol. 2018; 76(2): 376-380, doi: 10.5603/ KP.a2017.0209, indexed in Pubmed: 29131292.

7. Gräsner JT, Bossaert L. Epidemiology and management of cardiac arrest: what registries are revealing. Best Pract Res Clin Anaesthesiol. 2013; 27(3): 293-306, doi: 10.1016/j.bpa.2013.07.008, indexed in Pubmed: 24054508.

8. Gach D, Nowak JU, Krzych $\succeq$. Epidemiology of out-of-hospital cardiac arrest in the Bielsko-Biala district: a 12-month analysis. Kardiol Pol. 2016; 74(10): 1180-1187, doi: 10.5603/KP.a2016.0086, indexed in Pubmed: 27221961.

9. Perkins GD, Handley AJ, Koster RW, et al. Adult basic life support and automated external defibrillation section Collaborators. European Resuscitation Council Guidelines for Resuscitation 2015: Section 2. Adult basic life support and automated external defibrillation. Resuscitation. 2015; 95: 81-99, doi: 10.1016/j.resuscitation.2015.07.015, indexed in Pubmed: 26477420.

10. Kleinman ME, Brennan EE, Goldberger ZD, et al. Part 5: Adult Basic Life Support and Cardiopulmonary Resuscitation Quality: 2015 American Heart Association Guidelines Update for Cardiopulmonary Resuscitation and Emergency Cardiovascular Care. Circulation. 2015; 132(18 Suppl 2): S414-S435, doi: 10.1161/CIR.0000000000000259, indexed in Pubmed: 26472993.

11. Smereka J, Iskrzycki $k$, Makomaska-Szaroszyk E, et al. The effect of chest compression frequency on the quality of resuscitation by lifeguards. A prospective randomized crossover multicenter simulation trial. Cardiol J. 2018 [Epub ahead of print], doi: 10.5603/ CJ.a2018.0121, indexed in Pubmed: 30338845.

12. Wieczorek W, Kaminska H. Impact of a corpuls CPR Mechanical Chest Compression Device on chest compression quality during extended pediatric manikin resuscitation: a randomized crossover 
pilot study. Disaster Emerg Med J. 2017; 2(2): 58-63, doi: 10.5603/ DEMJ.2017.0012.

13. Chang MP, Idris AH. The past, present, and future of ventilation during cardiopulmonary resuscitation. Curr Opin Crit Care. 2017; 23(3): 188-192, doi: 10.1097/MCC.0000000000000415, indexed in Pubmed: 28402985.

14. Evrin T, Rusin M, Kacprzyk D, et al. Supraglottic airway devices - a conceit or the future of airway management? Disaster Emerg Med J 2018; 3(3):106-107. Disaster Emerg Med J. 2018; 3(3): 106-107, doi: 10.5603/DEMJ.2018.0023.

15. Smereka J, Madziala M, Szarpak L. Comparison of two infant chest compression techniques during simulated newborn cardiopulmonary resuscitation performed by a single rescuer: A randomized, crossover multicenter trial. Cardiol J. 2018 [Epub ahead of print], doi: 10.5603/ CJ.a2018.0090, indexed in Pubmed: 30155866.

16. Smereka J, Szarpak L, Rodríguez-Núñez A, et al. A randomized comparison of three chest compression techniques and associated hemodynamic effect during infant CPR: A randomized manikin study. Am J Emerg Med. 2017; 35(10): 1420-1425, doi: 10.1016/j. ajem.2017.04.024, indexed in Pubmed: 28433454.

17. Smereka J, Kaminska H, Wieczorek W, et al. Which position should we take during newborn resuscitation? A prospective, randomised, multicentre simulation trial. Kardiol Pol. 2018; 76(6): 980-986, doi: 10.5603/KP.a2018.0030, indexed in Pubmed: 29350383.

18. Majer J, Jaguszewski MJ, Frass M, et al. Does the use of cardiopulmonary resuscitation feedback devices improve the quality of chest compressions performed by doctors? A prospective, randomized, cross-over simulation study. Cardiol J. 2018 [Epub ahead of print], doi: 10.5603/CJ.a2018.0091, indexed in Pubmed: 30155865.

19. Iskrzycki L, Smereka J, Rodriguez-Nunez A, et al. The impact of the use of a CPRMeter monitor on quality of chest compressions: a prospective randomised trial, cross-simulation. Kardiol Pol. 2018; 76(3): 574-579, doi: 10.5603/KP.a2017.0255, indexed in Pubmed: 29297195.

20. Beesems SG, Koster RW. Accurate feedback of chest compression depth on a manikin on a soft surface with correction for total body displacement. Resuscitation. 2014; 85(11): 1439-1443, doi: 10.1016/j. resuscitation.2014.08.005, indexed in Pubmed: 25150184.

21. Kurowski A, Szarpak $Ł$, Bogdański $Ł$, et al. Comparison of the effectiveness of cardiopulmonary resuscitation with standard manual chest compressions and the use of TrueCPR and PocketCPR feedback devices. Kardiol Pol. 2015; 73(10): 924-930, doi: 10.5603/KP.a2015.0084, indexed in Pubmed: 25985725.

22. Bhanji F, Donoghue AJ, Wolff MS, et al. Part 14: Education: 2015 American Heart Association Guidelines Update for Cardiopulmonary Resuscitation and Emergency Cardiovascular Care. Circulation. 2015; 132(18 Suppl 2): S561-S573, doi: 10.1161/CIR.0000000000000268, indexed in Pubmed: 26473002.
23. Brooks SC, Anderson ML, Bruder E, et al. Part 6: Alternative Techniques and Ancillary Devices for Cardiopulmonary Resuscitation: 2015 American Heart Association Guidelines Update for Cardiopulmonary Resuscitation and Emergency Cardiovascular Care. Circulation. 2015; 132(18 Suppl 2): S436-S443, doi: 10.1161/CIR.0000000000000260, indexed in Pubmed: 26472994.

24. Nagafuchi K, Hifumi T, Nishimoto N, et al. Chest Compression Depth and Rate - Effect on Instructor Visual Assessment of Chest Compression Quality. Circ J. 2019; 83(2): 418-423, doi: 10.1253/circj. CJ-18-0952, indexed in Pubmed: 30606940.

25. Magliocca $A$, Olivari $D$, De Giorgio $D$, et al. LUCAS Versus Manual Chest Compression During Ambulance Transport: A Hemodynamic Study in a Porcine Model of Cardiac Arrest. J Am Heart Assoc. 2019; 8(1): e011189, doi: 10.1161/JAHA.118.011189, indexed in Pubmed: 30590977.

26. Wagner M, Bibl K, Hrdliczka E, et al. Effects of Feedback on Chest Compression Quality: A Randomized Simulation Study. Pediatrics. 2019 [Epub ahead of print], doi: 10.1542/peds.2018-2441, indexed in Pubmed: 30700565.

27. Abelsson A, Lundberg L. Prehospital CPR training performed with visual feedback. Disaster Emerg Med J. 2018; 3(2): 41-45, doi: 10.5603/demj.2018.0010.

28. Truszewski Z, Szarpak L, Kurowski A, et al. Randomized trial of the chest compressions effectiveness comparing 3 feedback CPR devices and standard basic life support by nurses. Am J Emerg Med. 2016; 34(3): 381-385, doi: 10.1016/j.ajem.2015.11.003, indexed in Pubmed: 26612703.

29. Sahyoun C, Siliciano C, Kessler D. Use of Capnography and Cardiopulmonary Resuscitation Feedback Devices Among Prehospital Advanced Life Support Providers. Pediatr Emerg Care. 2018 [Epub ahead of print], doi: 10.1097/PEC.0000000000001685, indexed in Pubmed: 30601348.

30. González-Otero DM, Ruiz de Gauna S, Ruiz J, et al. Performance of cardiopulmonary resuscitation feedback systems in a long-distance train with distributed traction. Technol Health Care. 2018; 26(3): 529-535, doi: 10.3233/THC-181241, indexed in Pubmed: 29710761.

31. Brown LL, Lin Y, Tofil NM, et al. International Network for Simulation-based Pediatric Innovation, Research, Education CPR Investigators (INSPIRE). Impact of a CPR feedback device on healthcare provider workload during simulated cardiac arrest. Resuscitation. 2018; 130 : 111-117, doi: 10.1016/j.resuscitation.2018.06.035, indexed in Pubmed: 30049656.

32. Abelairas-Gómez C, Rey E, González-Salvado V, et al. Acute muscle fatigue and CPR quality assisted by visual feedback devices: A randomized-crossover simulation trial. PLoS One. 2018; 13(9): e0203576, doi: 10.1371/journal.pone.0203576, indexed in Pubmed: 30231037. 